\title{
Bacterial DNA repair genes and their eukaryotic homologues: 5. The role of recombination in DNA repair and genome stability ${ }^{\star}$
}

\author{
Anetta Nowosielska ${ }^{{ }^{2}}$ \\ Program in Molecular Medicine, University of Massachusetts Medical School, Worcester, USA
}

Received: 31 August, 2007; revised: 12 September, 2007; accepted: 18 September, 2007

available on-line: 23 September, 2007

\begin{abstract}
Recombinational repair is a well conserved DNA repair mechanism present in all living organisms. Repair by homologous recombination is generally accurate as it uses undamaged homologous DNA molecule as a repair template. In Escherichia coli homologous recombination repairs both the double-strand breaks and single-strand gaps in DNA. DNA double-strand breaks (DSB) can be induced upon exposure to exogenous sources such as ionizing radiation or endogenous DNA-damaging agents including reactive oxygen species (ROS) as well as during natural biological processes like conjugation. However, the bulk of double strand breaks are formed during replication fork collapse encountering an unrepaired single strand gap in DNA. Under such circumstances DNA replication on the damaged template can be resumed only if supported by homologous recombination. This functional cooperation of homologous recombination with replication machinery enables successful completion of genome duplication and faithful transmission of genetic material to a daughter cell. In eukaryotes, homologous recombination is also involved in essential biological processes such as preservation of genome integrity, DNA damage checkpoint activation, DNA damage repair, DNA replication, mating type switching, transposition, immune system development and meiosis. When unregulated, recombination can lead to genome instability and carcinogenesis.
\end{abstract}

Keywords: Escherichia coli, homologous recombination, replication forks, DNA repair, DSB

\section{INTRODUCTION}

Genomic DNA is constantly subjected to damages. Some repair systems simply reverse DNA modifications, for instance Ada methyltrasferase (reviewed in Nieminuszczy \& Grzesiuk, this issue), some of them need to excise modified nucleotide from DNA in a process called base excision repair (reviewed in Krwawicz, this issue) or remove whole DNA fragment containing a lesion, which is characteristic for nucleotide excision repair (NER) and methylation-directed mismatch repair (MMR) (reviewed in Maddukuri et al., this issue, and Arczewska \& Kusmierek, this issue, respectively).

While mentioned repair systems have evolved to mend specific DNA modification and incorrectly paired bases, recombination is specialized in recognition and repair of DNA breaks.

\footnotetext{
^ This paper is dedicated to our mentors: David Shugar, Celina Janion, Irena Pietrzykowska, Zofia Zarębska and Daniela Barszcz, scientists from the Institute of Biochemistry and Biophysics Polish Academy of Sciences, who contributed to a great extent to the development in the field of DNA damage, mutagenesis and repair.

Corresponding author: Anetta Nowosielska, Program in Molecular Medicine, University of Massachusetts Medical School, Biotech 2, 373 Plantation Street, Worcester MA, USA, 01605, tel.: (508) 856 0057; fax: (508) 856 3820; e-mail: Anetta.Nowosielska@umassmed.edu

Former addresses: Department of Biochemistry and Molecular Pharmacology, University of Massachusetts Medical School, 364 Plantation Street, Worcester MA, 01605, USA; Institute of Biochemistry and Biophysics PAS, A. Pawińskiego 5a, 01-106 Warszawa, Poland.

Abbreviations: DSB, double-strand break, DSE, double-strand end; HR, homologous recombination; RF, replication fork; RFR replication fork reversal.
} 
Homologous recombination consists of three stages which are common for prokaryotes and eukaryotes: presynapsis, where DSB or gap is formed and the resulting DNA end is being prepared for recombination; synapsis, where physical connection between the recombinogenic substrate and an intact homologous duplex DNA template is generated leading to formation of heteroduplex (hybrid) molecules; and postsynapsis, where DNA synthesis from the invading $3^{\prime}$ end takes place followed by the resolution of junction intermediates.

In Escherichia coli there are two major mechanisms of homologous recombination: the RecB pathway, which fixes double-strand breaks, and the RecF pathway, which repairs daughter strand gaps (Fig. $1 a$ and $b$, respectively). Both of them require RecA recombinase for homology recognition and DNA strand exchange.

\section{RecA PROTEIN}

The RecA protein has a DNA-dependent ATPase activity, both double-strand and single-strand DNA binding activity, homologous DNA pairing activity, and strand exchange activity.

In addition to its recombinational function, RecA is also important in the induction of the SOS response - global DNA repair and DNA damage tolerance (Little, 1991). The co-protease activity of the RecA filament formed on the 3' end of single-stranded DNA stimulates autocleavage of the LexA repressor, which inhibits expression of a variety of genes products involved in faithful DNA repair systems, among them some components of homologous recombination $(\operatorname{ruv} A$, $\operatorname{ruv} B, \operatorname{recN}$ and recA) (Friedberg et al., 1995). The co-protease activity of the RecA-ssDNA filament facilitates the autocatalytic cleavage of UmuD, a component of DNA polymerase V (Tang et al., 1999; Pham et al., 2002), and stimulates DNA synthesis on a damaged template by PolV (Schlacher et al., 2006).

The structure of RecA protein was elucidated in 1992 (Story et al., 1992). RecA protein first binds to the single-stranded or gapped DNA substrate, producing a right-handed helical filament containing one RecA monomer for every three nucleotides or base pairs of DNA. Next, a homologous duplex DNA is aligned to produce a nascent hybrid DNA. The RecA filament extension proceeds in the $5^{\prime}$ to $3^{\prime}$ direction along the DNA (Shan \& Cox, 1996). Extension is rapid and occurs via cooperative addition of RecA monomers to the 3 '-proximal end of the filament. RecA filament disassembly requires ATP hydrolysis and also occurs in the $5^{\prime}$ to $3^{\prime}$ direction.

\section{PRESYNAPSIS IN RecB PATHWAY}

The key player in homologous recombination in E. coli is RecBCD, a $330 \mathrm{kDa}$ protein, which processes blunt DNA double strand ends (DSE) and loads RecA protein on the $3^{\prime}$ tail of single stranded DNA. Thanks to its complex architecture the RecBCD enzyme possess a nuclease and bipolar helicase activities. One of the components of RecBCD complex, $\operatorname{Rec} B$, is a nuclease and a $3^{\prime}-5^{\prime}$ helicase. Another one, RecD, also has helicase activity however it unwinds dsDNA in the $5^{\prime}$ to $3^{\prime}$ direction. Both helicases, have opposite polarities and travel in the same direction on both strand of the DNA duplex. RecD is the fast helicase acting on the $5^{\prime}$ DNA end, while RecB is the slow helicase acting on the $3^{\prime}$ end of DNA. The different processivities of these helicases lead to the formation of a long $5^{\prime}$ strand and a short $3^{\prime}$ strand with an expanding single stranded loop which has been observed in electron micrographs (Taylor \& Smith, 1980). The resolution of the RecBCD crystal structure obtained by two laboratories (Dillingham et al., 2003; Taylor \& Smith, 2003) indicates that the DNA duplex fed to the RecBCD holoenzyme is split across the RecC subunit and each single DNA strand is directed towards different helicase subunits. The $5^{\prime}$ tail is fed to the RecD helicase and then onto the nuclease domain of RecB for digestion. The $3^{\prime}$ tail is fed along a channel within the protein complex that emerges at the nuclease active site. As this strand goes directly to the nuclease active site it is digested with a higher processivity in comparison to the $5^{\prime}$ tail which is located in a less favorable position. The RecC subunit is responsible for the DNA scanning and recognition of the Chi sequence: 5'-GCTGGTGG-3' (a 'crossover hotspot instigator'). Upon encountering a Chi site the final cleavage is introduced within a few bases from it and then RecC binds tightly to $3^{\prime}$ end thus preventing its further digestion. From that moment the $5^{\prime}$ tail is able to access the nuclease site more freely and is cleaved more frequently. These structural data elegantly explain why, after encountering $\mathrm{Chi}$, the RecBCD complex pauses, its nuclease activity decreases and its polarity switches, the events for the first time visualized by Kowalczykowski's laboratory (Handa et al., 2005). In the next step RecBCD loads the RecA protein on the $3^{\prime}$ end to initiate homologous pairing and strand exchange (Anderson et al., 1997; Arnold et al., 2000; Churchill et al., 2000).

\section{PRESYNAPSIS IN RecF PATHWAY}

The RecF pathway, under natural circumstances, is responsible for single strand gap repair and is composed of the following proteins: $\mathrm{RecF}, \mathrm{RecO}, \mathrm{RecR}$, 
A. double-strand break repair

1

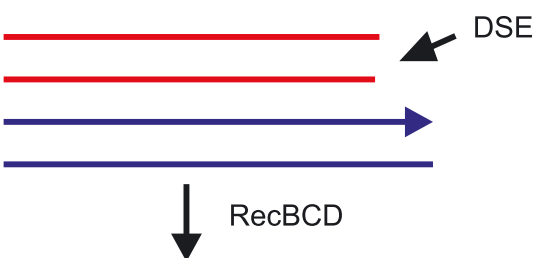

2

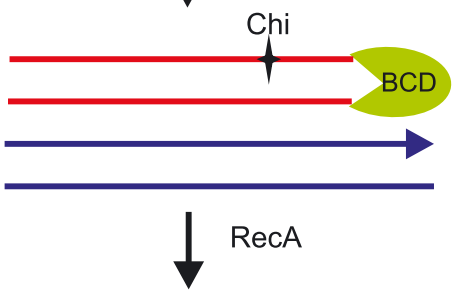

3

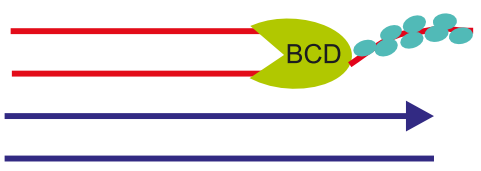

\rfloor RuvABC or RecG

4

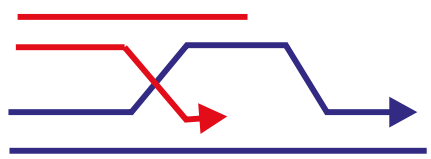

5

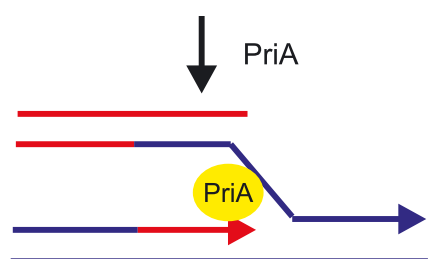

B. single-strand gap repair

1

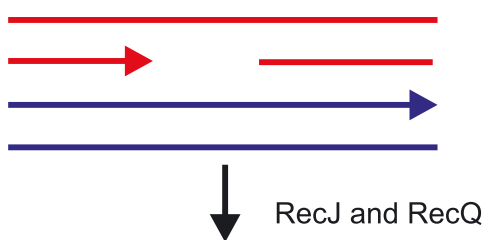

2

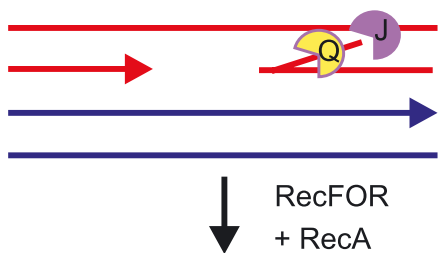

3

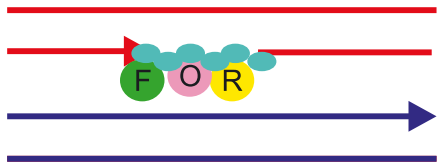

RuvABC or RecG

4

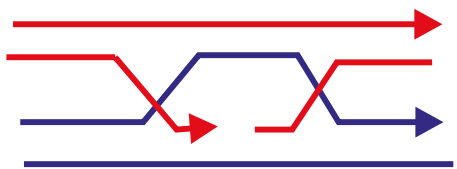

5

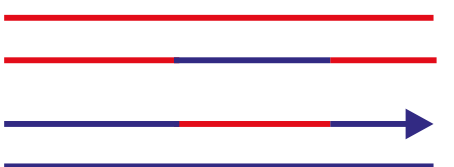

Figure 1. Homologous recombination.

A. Double strand breaks repair: 1. Double strand end (DSE) is generated in DNA and RecBCD binds to it; 2 . RecBCD unwinds a duplex and degrades it; 3. Till encounters Chi site, then RecBCD switches from its exonuclease $\mathrm{V}$ activity to recombinase activity and loads RecA on the 3' single strand to produce RecA filament; 4 . The RecA filament invades homologous DNA strand and Holliday junction is formed to which RuvABC resolvase or RecG helicase binds; 5 . The Holliday junction is resolved, and resulting D-loop is acted upon by PriA, to allow replisome assembly. B. Single strand gap repair: 1. Single strand gap is formed in DNA; 2. RecQ and RecJ start to unwind and degrade single-stranded DNA region; 3. The RecFOR proteins bind to it and load RecA; 4. The RecA filament promotes strand-exchange and the Holliday junction is resolved by RuvABC or RecG proteins; 5. Nicked DNA strand is repaired. RecBCD (light green indented oval); the RecA filament (light blue ovals); PriA (yellow circle); RecJ (purple indented circle); RecQ (light yellow indented circle); RecF (green circle); RecO (pink circle); RecR (yellow circle).

RecJ, RecQ and RecN. These single strand gaps (also called daughter strand gaps) in DNA are often formed when the replication fork encounters a non-coding lesion in a template DNA and reinitiates downstream from it. However when the RecBCD pathway is inactivated by mutation in one of the genes encoding its components, the recombinational defect is suppressed by mutations in $s b c A, s b c B$, or $s b c C D$ genes, which activate the RecF pathway (Bidnenko et al., 1999; Kow- alczykowski et al., 1994; Kuzminov, 1999). In the RecF pathway, the $3^{\prime}$ ssDNA is prepared by RecQ helicase and RecJ $5^{\prime}$ to $3^{\prime}$ exonuclease, while RecA loading on the 3' tail is achieved by RecF, RecO and RecR (Lovett \& Kolodner, 1989; Kowalczykowski, 2000).

The $\mathrm{RecF}, \mathrm{RecO}$, and RecR proteins are involved in establishment of a RecA filament on DNA and modulate both its assembly and disassembly (Shan et al., 1997). E. coli RecF protein (40.5 kDa) 
binds both dsDNA and ssDNA in vitro, and has a weak dsDNA-dependent ATPase activity in vivo (Sandler, 1996; Webb, 1999; Rangarajan et al., 2002). The RecF protein physically interacts with RecR $(22 \mathrm{kDa})$ and the latter one also interacts with $\mathrm{RecO}(26 \mathrm{kDa})$. The RecOR proteins stimulate displacement of SSB proteins from DNA, thus facilitating RecA nucleation. The RecF protein seems to interfere with this function (Hobbs et al., 2007). However, RecF may position RecOR on specific DNA sites to initiate presynaptic complex formation (Sandler \& Clark, 1994). RecFR proteins can also prevent the RecA filament from expanding beyond the single strand gap. It has been shown that RecF protein crystallized from Deinococcus radiodurans shares structural similarity with the eukaryotic Rad50 protein (Koroleva et al., 2007).

The sequenced $\mathrm{recO}$ gene encodes a $27 \mathrm{kDa}$ protein and promotes ATP-independent annealing of complementary DNA strands (Luisi-DeLuca et al., 1994). The RecO-SSB DNA renaturation activity is similar to that promoted by the eukaryotic Rad52 protein (Mortenson et al., 1996; Reddy et al., 1997; Sugiyama et al., 1998).

The RecQ protein is an ATP-dependent DNA helicase which translocates unidirectionally $3^{\prime}$ to $5^{\prime}$ along one strand of the duplex. In humans there are five homologs of RecQ helicases: RECQL, BLM, WRN, RECQ4 and RECQ5. The defects in eukaryotic RecQ helicases lead to premature aging and cancer predisposition, whereas a null mutation in E. coli recQ gene results in a 30-fold increase in illegitimate recombination (Hanada, 1997). RecJ is a $60 \mathrm{kDa}$ protein with a 5'-3' exonucleolytic activity (Lovett \& Kolodner, 1989). It has also been shown that RecJ and RecQ proteins process replication forks, before resumption of replication, thus preventing stalled replication forks from unnecessary recombination event (Hanawalt \& Courcelle, 2001). The enzymatic activities of RecQ and RecJ have a key role in enabling the RecF pathway to act on DSBs in the absence of an active RecB pathway (Amundsen, 2003).

Another E. coli protein belonging to the RecF pathway is encoded by the $r e c N$ gene. The RecN protein is a member of the structural maintenance of chromosomes (SMC) family (Rostas et al., 1987). RecN is strongly induced during the SOS response and has been implicated in DNA double strand break repair (Meddows et al., 2005) Its concentration in a cell is tightly regulated, as the $\mathrm{RecN}$ protein has a short half-life and its degradation is dependent on the cytoplasmic protease ClpXP (Nagashima et al., 2006).

\section{REGULATION OF RecA FILAMENT FORMATION}

In addition to the RecFOR and RecBCD complexes mentioned above, many other proteins control the formation of the RecA filament in E. coli. The major competitors of the RecA filament formation are single-stranded DNA binding (SSB) proteins, which as their name implies, bind to single-stranded DNA (ssDNA) to protect it from degradation. SSB proteins are essential to DNA metabolism in all organisms. In E. coli, the ssb gene is indispensable for cell viability (Meyer et al., 1990; Lohman et al., 1994; Curth et al., 1996). The eukaryotic counterpart of SSB is the heterotrimeric replication protein A (RPA) (Brill \& Stillman, 1991; Ogawa et al., 1993). The SSB as well as RPA proteins inhibit RecA filament formation if they coat DNA before RecA binding (Lavery et al., 1990; Umezu et al., 1994; Shan et al., 1997; Shinohara \& Ogawa, 1998; New et al., 1998; Bork et al., 2001). The inhibitory action of SSB proteins on RecA nucleation is overcome in the bacterial cell by the RecOR protein complex (Bork et al., 2001; Morimatsu et al., 2003; Hobbs et al., 2007). On the other hand, SSB protein binding to DNA eliminates secondary structures to which the RecA protein would not be able to bind efficiently. Therefore, SSB binding to DNA enables RecA to form a contiguous RecA filament on the DNA (Kowalczykowski et al., 1987).

Assembly and disassembly of a RecA filament is also regulated by the interaction with many other proteins, such as: DinI protein which stabilizes RecA filaments (Lusetti et al., 2004); RecX protein which blocks RecA filament extension (Drees et al., 2004); RecF protein which antagonizes RecX inhibitory function (Lussetti et al., 2006), and finally UvrD helicase, which causes disruption of RecA filaments (Lovett et al., 1995; Petranovic et al., 2001; Veaute et al., 2005; for details see review by Cox, 2007).

In eukaryotes, Rad52, Rad51 paralogs and Rad54 are responsible for Rad51 filament formation (Wolner et al., 2003). As mentioned, eukaryotic recombinase Rad51 form a presynaptic filament (Sung et al. 2003) which formation is inhibited by RPA bound to ssDNA prior to Rad51 loading. This inhibitory effect in eukaryotes is overcome by Rad52 and Rad55-Rad-57 proteins (Sung, 1997). Rad52 protein interacts with both Rad51 and RPA (Shinohara et al., 1992; 1998). The Rad55-Rad57 heterodimer physically interacts with Rad51 and has an ssDNA-binding activity (Johnson \& Symington, 1995). It can stabilize the already assembled Rad51 presynaptic filament (Fortin \& Symington, 2002).

\section{POSTSYNAPTIC STAGE OF RecB AND RecF PATHWAYS}

The postsynaptic phase of homologous recombination requires housekeeping enzymes. In the last phase of the RecF pathway, gyrase and topoisomerase I are needed to relieve positive and negative 
DNA supercoiling, generated during RecA filament interaction with the homologous double-stranded template (Cunningham et al., 1981; Casuto, 1984). Additionally helicase II (UvrD), DNA polymerase I (PolI), replicative DNA helicase (DnaB), a catalytic subunit of PolIII (PolC/DnaE) and ligase are needed to enable the filling and closing of single-strand gaps. Genetic studies showed that completion of double-strand break repair also requires DNA gyrase, DNA Poll and DNA ligase (reviewed in Kuzminov, 1999).

\section{MIGRATION AND RESOLUTION OF BRANCHED DNA STRUCTURES}

The RuvAB protein complex is a molecular motor that can branch-migrate Holliday junctions, which result in extension of heteroduplex DNA between recombining DNA molecules (West, 2003). Similar reactions are catalyzed by RecG helicase (Lloyd \& Sharples, 1993; McGlynn \& Lloyd, 1999). The junction formed during strand invasion must be eventually resolved to restore linear duplexes. Depending on the configuration of Holliday junction breaks introduced by RuvC protein (a Holliday junction resolvase), the resulting DNA molecule may be identical with the parental one or changed if a crossover took place.

The RecA filament-promoted strand exchange generates a three strand junction such as a D-loop and the four strand junctions called Holliday junctions (Liu \& West, 2004). RuvA (22 kDa) recognizes the Holliday junction structure and binds to it as a tetramer (Tsaneva et al., 1992). RuvA, together with the RuvB protein (37 kDa), promotes branch migration of Holliday junctions. The RuvB molecular motor is an intrinsic ATP-dependent DNA helicase with a hexameric ring structure (West, 1997). It has low intrinsic affinity to DNA, however, a direct interaction with RuvA targets RuvB to the junction. RuvA tetramers bind to the junction to open it into a square planar conformation while two RuvB rings bind to the opposite arms of the junction. RuvB rings pull duplex DNA through their holes, causing the junction to branch-migrate (Him \& West, 1995)

RuvC is a $19 \mathrm{kDa}$ resolvase which binds to a Holliday junction as a dimer and introduces nicks on two DNA strands of the same polarity, at a degenerate sequence $5^{\prime}-(\mathrm{A} / \mathrm{T}) \mathrm{TT} \downarrow$ (GC)-3' (Eggleston $\&$ West, 2000). The nicks introduced by RuvC are sealed by ligase. Another ATP-dependent DNA helicase which binds Holliday junctions and translocates them is RecG helicase. However, the RecG activity is much weaker in comparison to the RuvAB complex. While RuvAB tranlocates ssDNA in the $5^{\prime}$ to $3^{\prime} \mathrm{di}-$ rection, RecG translocates it in the $3^{\prime}$ to $5^{\prime}$ direction.
RecG has specificity for branched DNA molecules, in particular Holliday junctions and replication forks (Lloyd \& Sharples, 1993; McGlynn \& Lloyd, 1999; 2001). Biochemical studies revealed that RecG is active as a monomer (McGlynn et al., 2000) and catalyzes the interconversion of forks and junctions (McGlynn \& Lloyd, 2000; McGlynn et al., 2001), thus facilitating the interplay between DNA replication, recombination, and repair (Briggs et al., 2004).

The E. coli RuvC enzyme has high specificity for cleavage of Holliday junctions, but mutants lacking RuvC do not show a strong deficiency in conjugational recombination unless an additional mutation is present in recG (Lloyd, 1991; Benson \& West, 1994). Another protein engaged in Holliday junction resolution in E. coli, RusA, is encoded by a defective prophage. It is a DNA structure-specific endonuclease which introduces symmetrically paired incisions 5 ' to CC (Sharples et al., 2002).

While in E. coli migration of the Holliday junction takes place with the help of the RuvABC and RecG proteins, in eukaryotes it is achieved by the Rad54 protein. Rad54 is a member of the Swi2/ Snf2 family of SF2 helicases (Pazin \& Kadonaga, 1997), which translocates on dsDNA but it does not display a strand displacement activity typical for a helicase. Rad54 remodels DNA structure, chromatin structure and Rad51-dsDNA complexes (Heyer et al., 2006).

There have been intensive studies on identifying the eukaryotic counterparts of Holliday-junction endonucleases. Recently, it has been shown that Rad51 paralogs Rad51C and Xrcc3 participate in the Holliday junction resolution (Liu \& West, 2004). Other studies in yeast and human cells have shown participation of a protein complex containing Mus81 with its partner MMS4 or Eme1 in resolving Holliday structure during meiosis (Boddy et al., 2001; Chen et al., 2001; Kaliraman et al., 2001; Constantinou et al., 2002; Ciccia et al., 2003; Gaillard et al., 2003).

Alternatively, Holliday junction in eukaryotes can be separated by the combined action of RecQlike helicases and a topoisomerase III (Heyer et al., 2003).

\section{REPAIR OF STALLED REPLICATION FORKS}

Replication blocks are quite frequent in the every living cell's life. Their causes range from the malfunction of the replicative machinery to the damage to DNA by the UV treatment. If replication forks encounter a lesion which prevents their progression, the cell employs restart systems in order to ensure replication completion. In E. coli stalled replication forks can be processed by DNA helicases, nucleases and recombinational proteins. Once rep- 
lication fork is reconstituted, the replisome can be reloaded, and the lesion, which imposed replication block, must be removed (Heller \& Marians, 2006). In E. coli three proteins: PriA, Rep and UvrD are $3^{\prime}-5^{\prime}$ helicases involved in the restart of stalled replication forks (Heller \& Marians, 2005; Flores et al., 2005).

The PriA protein is highly conserved in bacteria. Inactivation of this protein, which is important for replication restart, leads to reduced viability, slow growth, sensitivity to rich medium and induction of the SOS response. PriA contains a crucial 3'-termini binding pocket responsible for high affinity binding to D-loops and stalled fork structures that contain a nascent leading strand with the $3^{\prime}-\mathrm{OH}$ end near to the fork junction (Mizukoshi et al., 2003). PriA interaction with DNA induces binding of the PriB protein which stabilizes the PriA-DNA interaction and facilitates recruitment of DnaT (Liu \& Marians, 1999). This multiprotein-DNA complex is responsible for recognizing the correct DNA structure and helps to remove recombination and other proteins such as RecA or SSB associated with the processed DNA structure, and unwinds duplex DNA to load the DnaB replicative helicase. Then, DnaB is loaded into the complex with a help of the DnaC protein, which does not retain in the complex. Next, DnaB interacts with PolIII holoenzyme and the DnaG primase to reconstitute replisome (Sandler, 2001). PriAdirected replication restart targets $\mathrm{D}$ loops, $\mathrm{R}$ loops and stalled replication forks with nascent leading strand. PriC-directed replisome loading, which depends on priC and rep genes products, is limited. It targets only a subset of stalled replication forks with a gap generated when the nascent leading strand encounters blocking lesion while the lagging strand continues to unwind (Heller \& Marians, 2006).

Another DNA helicase, Rep, possessing a $3^{\prime}$ to $5^{\prime}$ translocation activity is required for the optimal progression of replication forks due to its ability to remove proteins in front of the replication forks. A lack of this protein also contributes to frequent replication fork stalling (Heller \& Marians, 2005). Rep also takes part in the reconstitution of stalled replication forks by unwinding nascent lagging-strand DNA in a similar way to PriA. Rep is also proposed to act in the PriC pathway as its helicase activity is stimulated by PriC protein, therefore it is suggested that Rep is recruited to the stalled replication forks which are the substrate for the PriC helicase (Sandler, 2000; Heller \& Marians, 2005).

The E. coli UvrD protein is a $3^{\prime}$ to $5^{\prime}$ helicase, which prefers to unwind DNA with a $3^{\prime}$ single-stranded overhang (Matson, 1986). UvrD is also able to unwind DNA from a nicked substrate and a blunt end (Runyon et al., 1990). The UvrD protein is a component of nucleotide excision repair (NER) and methyl-directed mismatch repair (Lahue et al.,
1989; Dao \& Modrich 1998). In addition, UvrD takes part in homologous recombination initiated by RecFOR in $\operatorname{rec} B C \operatorname{sbcBC}$ mutants (Mendonca et al., 1993). At blocked replication forks, $\mathrm{UvrD}$ dismantles the RecA filament, thus allowing replication fork reversal and proper replication restart (Flores et al., 2004). The Srs2 protein found in yeast is a homolog of E. coli Rep and UvrD helicases. Srs2 is an ATPdependent DNA helicase, that is required for DNA damage checkpoint responses and that modulates the efficiency of homologous recombination and (Van Komen, 2003).

\section{INVOLVEMENT OF RECOMBINATION PROTEINS IN REPLICATION FORK REVERSAL (RFR)}

Extensive studies in Benedicte Michel's laboratory showed that certain replication mutants: rep coding helicase, dnaE, encoding catalytic subunit of PolIII, dnaN, coding $\beta$ clamp, and holD, which encodes $\psi$, a component of $\gamma$ complex clamp loader, suffer frequent replication fork arrest (Grompone et al., 2002; Baharoglu et al., 2006). This group showed that these mutants were synthetically lethal with $\operatorname{rec} B C D$ inactivation but not with $\operatorname{rec} A$ deficiency, excluding dnaN mutant. Rep lethality was suppressed by the additional inactivation of ruvAB. These results contributed to the model of replication fork reversal in which nascent lagging and leading strand ends anneal creating double strand end adjacent to a Holliday structure. This structure is recognized by RuvAB proteins which bind to it. In $R e c B C D^{+}$cells RecBCD holoenzyme binds to DSE and degrades it up to the Holliday junction stabilized by RuvAB proteins. Next it displaces RuvAB complex leaving reconstituted $\mathrm{RF}$, to which the replisome can be loaded by the PriA pathway. RecBCD enzyme can also encounter a Chi site during DSE degradation and initiate strand invasion and exchange, which also results in replication fork recovery. In the absence of RecBCD proteins a Holliday junction formed by a reversed fork is processed by RuvAB proteins which results in its breakage (Baharoglu et al., 2006).

This group also showed that the initiation of replication fork reveral can vary among studied replication mutants.

Studies in Michel's laboratory showed that, in $d n a B$ mutants, defective in a replicative helicase, the initial stage of RFR requires RecA protein. They have proposed a model in which RecA alone is needed to direct RFR in this mutant (Seigneur et al., 2000). Further research revealed that in other temperature sensitive replication mutants, dnaE and holD, RFR was dependent on RuvAB, which probably by itself catalyzes the conversion of replication fork to Holliday junction. Only partial dependence on RuvAB was 
observed for the rep mutant, which was defective in another DNA helicase. Studies on temperature sensitive mutants defective in catalytic subunit of PolIII (dnaE) and clamp (dnaN) showed a UvrD requirement for RFR in the presence of the RecF pathway. These results suggest a model in which RecFORJQ proteins promote RecA-binding at forks thus preventing RFR. It was concluded that fork processing by these proteins result in a lethal structure and that the deleterious action of RecQ, RecJ, RecF, RecO and RecR proteins in dnaE and dnaN mutants is counteracted by UvrD function (Flores et al., 2005).

Once the replication fork is restored it is targeted for replisome reassembly.

Depending on the way the replication fork is processed the replisome loading on reconstituted replication fork is coordinated by the PriA or PriCdependent pathways (Sandler et al., 2001).

\section{PREVENTION OF DRUG-INDUCED CYTOXICITY}

Cisplatin (cis-diamminedichlorideplatinum (II)) is a popular chemotherapeutic drug widely used in cancer treatment, particularly effective against testicular tumors (Einhorn, 2002). Cisplatin binds to the N7 atom of purine bases in DNA to form predominantly 1,2-d(GpG), 1,2-d(ApG) and $1,3-\mathrm{d}(\mathrm{GpNpG})$ intrastrand cross-links, and a small percentage of interstrand crosslinks (Eastman, 1983; Fichtinger-Schepman, 1985), suggesting that cisplatin intrastrand crosslinks between adjacent purines are the biologically important adducts since they efficiently block progression of DNA polymerases in vitro and in vivo (Pinto \& Lippard, 1985). Studies on the cytotoxic effect of this drug in E. coli showed that homologous recombination contributes to cisplatin resistance (Zdravesky et al., 2000; Nowosielska \& Marinus, 2004). Subsequent studies on dam strains, deficient in Dam methyltransferase, revealed that the extensive number of DNA double strand breaks is generated in response to cisplatin. This observation led to conclusion, that the majority of cisplatin-triggered breaks are formed as a result of replication fork collapse on gaps introduced by mismatch repair processing platinated DNA (Nowosielska et al., 2005; Nowosielska \& Marinus, 2007).

It has been shown recently that homologous recombination protects also from cytotoxicity induced by methylating agents (Nowosielska et al., 2006). These results suggested that single-strand gaps and DSBs are produced by the replication fork collapse at blocking lesions or at single-strand nicks produced by AP-endonucleases (Nowosielska et al., 2006). However, in contrast to cisplatin, only a small fraction of methylation-induced DSBs is generated during replication (Nowosiel- ska \& Marinus, 2007) while the majority of them resulted from the interference of two repair systems processing methylated DNA (Nowosielska \& Marinus, 2007).

\section{HUMAN DISEASES CAUSED BY MUTATIONS IN RECOMBINATIONAL REPAIR}

The complexity and significance of homologous recombination in preservation of genome integrity can be better realized while studying human disorders caused by its malfunction. Increased or decreased frequencies of HR have been found in cancer cells and cancer-prone hereditary human disorders characterized by mutations in genes playing a role in HR, such as ATM, BRCA, BLM, and WRN genes.

Ataxia telangiectasia mutated (ATM) is a serine/threonine-specific protein kinase that is recruited and activated by DNA double-strand breaks. ATM kinase deficiency causes ataxia telangiectasia (AT), a syndrome characterized by increased sensitivity to ionizing radiation, cerebellar degeneration, oculocutaneous telangiectasia, immunodeficiency, aging and increased risk of cancers such as lymphoma and leukemia (Frappart \& McKinnon, 2006).

Mutations in BRCA1 and BRCA2 were identified as they predisposing to breast cancer (Miki et al., 1994; Wooster et al., 1995). Brca2 controls DNA binding by Rad51. Mutations in BRCA2 cause Fanconi anemia (Mathew, 2006). This genetic disorder increases susceptibility to several types of leukemia, and to cancers affecting ovaries, prostate and pancreas. It has been shown recently that the Brca2 protein interacts with the Dss1 protein, a 70-amino-acid protein that has been associated with the developmental disorder split hand/split foot malformation (Yang et al., 2002). The Dss1 protein is also involved in recombinational repair, and mutation in the DSS1 gene has the same effect as defects in the BRCA2 homolog (Kojic et al., 2003).

NBS1 mutations cause Nijmegen breakage syndrome, characterized by microcephaly, immunodeficiency and high incidence of cancer. The NBS1 gene product associates in vivo with Mre11 and Rad50 proteins to form the Mre11-Rad50-Nbs1 complex which plays pivotal roles in eukaryotic DNA double strand break repair, meiotic recombination and telomere maintenance (Digweed \& Sperling, 2004).

Mutations in three human homologs of RecQ helicase: BLM, WRN and RECQ4 contribute to genetic diseases. Defects in BLM lead to Bloom's syndrome (BS), in WRN to Werner syndrome (WS), and mutations in RECQ4 lead to RothmundThompson syndrome (RTS), RAPALIDINO, and 
Baller-Gerold syndrome (BGS). BS, WRN and RTS syndromes cause chromosomal instability, a predisposition to cancer and in the case of RTS, premature aging. People with RTS displays growth deficiency, photosensitivity with poikilodermatous skin changes. RAPALIDINO syndrome is an autosomal recessive disorder characterized by radial hypoplasia/aplasia, patellae hypoplasia/aplasia, and cleft or highly arched palate, little size, $\underline{\text { limb malformation, }}$ diarrhoea and dislocated joints, nose slender and normal intelligence. BGS is another recessive autosomal condition characterized by radial aplasia/hypoplasia and craniosynostosis (Sharma et al., 2006; Hanada \& Hickson, 2007). RecQ has been also reported in the maintenance of telomeres. Both the BLM and WRN proteins have been shown to interact with TRF2 telomere-binding protein (Opresco et al., 2002). The yeast homolog of RecQ, Sgs1, participates in a Rad52-dependent recombinational pathway of telomere maintenance in telomerasenegative mutants (Azam et al., 2006). The Rad51D protein, which is a RAD51 paralog, was shown to associate with telomeres and prevent their dysfunction (Tarsounas, 2004) and Rad54, which belong to the chromatin remodeling family, was found to act at telomeres. Its deficiency resulted in telomere shortening and telomere fusions (Jaco, 2003). To explain role of homologous recombination in telomere protection and elongation of telomeres two mechanisms involving inter- and intra-telomere homologous recombination were recently proposed (Tarsounas \& West, 2007).

\section{SUMMARY}

Homologous recombination is involved in a variety of DNA transactions. Its activity contributes to genetic diversity, repair of DNA double-stranded breaks (DSBs) (Paques \& Haber, 1999) and restart of stalled DNA replication forks (Michel et al., 2001; Heller \& Marians, 2006). In eukaryotes it is also responsible for telomere length maintenance (Cox et al., 2000; West, 2003). The defects in homologous recombination result in sensitivity to variety of genotoxic agents, such as cisplatin and methylating agents (Zdraveski et al., 2000; Nowosielska et al., 2004; Nowosielska \& Marinus, 2006). The malfunction of homologous recombination causes mitotic and meiotic chromosome aberrations, destabilization of the genome (Kolodner, 2000) and cancer (Jasin, 2002).

\section{REFERENCES}

Amundsen SK (2003) Interchangeable parts of the Escherichia coli recombination machinery Cell 112: 741744 .
Anderson DG, Kowalczykowski SC (1997) The translocating RecBCD enzyme stimulates recombination by directing RecA protein onto ssDNA in a chi-regulated manner. Cell 90: 77-86.

Arczewska K, Kusmierek J (2007) Bacterial DNA repair genes and their eukaryotic homologues: 2. Role of bacterial mutator gene homologues in human disease. Overview of nucleotide pool sanitization and mismatch repair systems. Acta Biochim Polon 54: 435-457.

Arnold DA, Kowalczykowski SC (2000) Facilitated loading of RecA protein is essential to recombination by RecBCD enzyme. J Biol Chem 275: 12261-12265.

Azam M, Lee JY, Abraham V, Chanoux R, Schoenly KA, Johanson FB (2006) Evidence that the S. cerevisiae Sgs1 protein facilitates recombinational repair of telomeres during senescence. Nucleic Acids Res 34: 506-516.

Baharoglu Z, Petranovic M, Flores M-J, Michel B (2006) RuvAB is essential for replication forks reversal in certain replication mutants. EMBO J 25: 596-604.

Baharoglu Z, Petranovic M, Flores MJ, Michel B (2006) Ru$\mathrm{VAB}$ is essential for replication forks reversal in certain replication mutants. EMBO J 25: 596-604.

Benson FE, West SC (1994) Substrate specificity of the Escherichia coli RuvC protein. Resolution of three- and four-stranded recombination intermediates. J Biol Chem 269: 5195-201.

Bidnenko V, Seigneur M, Penel-Colin M, Bouton MF, Ehrlich SD, Michel B (1999) sbcS sbcC null mutations allow RecF-mediated repair of arrested replication forks in rep recBC mutants. Mol Microbiol 33: 846-857.

Boddy MN, Gaillard PH, McDonald WH, Shanahan P, Yates JR 3rd, Russell P (2001) Mus81-Eme1 are essential components of a Holliday junction resolvase. Cell 107: 537-748.

Bork JM, Cox MM, Inman RB (2001) The RecOR proteins modulate RecA protein function at $5^{\prime}$ ends of singlestranded DNA. EMBO J 20: 7313-722.

Briggs GS, Mahdi AA, Weller GR, Wen Q, Lloyd RG (2004) Interplay between DNA replication, recombination and repair based on the structure of RecG helicase. Philos Trans $R$ Soc Lond B Biol Sci 359: 49-59.

Briggs GS, Mahdi AA, Wen Q, Lloyd RG (2005) Binding by the substrate specificity (Wedge) domain of RecG helicase suggests a role in processivity. J Biol Chem 280: 13921-13927.

Brill SJ, Stillman B (1991) Replication factor-A from Saccharomyces cerevisiae is encoded by three essential genes coordinately expressed at S phase. Genes Dev 5: 15891600 .

Cassuto E (1984) Formation of covalently closed heteroduplex DNA by the combined action of gyrase and RecA protein. EMBO J 3: 2159-2164.

Cassuto E, West SC, Howard-Flanders P (1982) Can recA protein promote homologous pairing between duplex regions of DNA? EMBO J 1: 821-825.

Chen XB, Melchionna R, Denis CM, Gaillard PH, Blasina A, Van de Weyer I, Boddy MN, Russell P, Vialard J, McGowan CH (2001) Human Mus81-associated endonuclease cleaves Holliday junctions in vitro. Mol Cell 8: 1117-1127.

Churchill JJ, Kowalczykowski SC (2000) Identification of the RecA protein-loading domain of RecBCD enzyme. J Mol Biol 297: 537-542.

Ciccia A, Constantinou A, West SC (2003) Identification and characterization of the human Mus81-Eme1 endonuclease. J Biol Chem 278: 25172-25178.

Constantinou A, Chen XB, McGowan CH, West SC (2002) Holliday junction resolution in human cells: two junc- 
tion endonucleases with distinct substrate specificities. EMBO J 21: 5577-5585.

Courcelle J, Hanawalt PC (2001) Participation of recombination proteins in rescue of arrested replication forks in UV-irradiated Escherichia coli need not involve recombination. Proc Natl Acad Sci USA 98: 8196-8202.

Cox MM (2007) Regulation of bacterial RecA protein function. Crit Rev Biochem Mol Biol 42: 41-63.

Cox MM, Goodman MF, Kreuzer KN, Sherratt DJ, Sandler SJ, Marians KJ (2000) The importance of repairing stalled replication forks. Nature 404: 37-41.

Cunningham D, Pembroke JT, Stevens E (1981) cis-Platin um(II)diamminodichloride-induced mutagenesis in $E$. coli K12: crowding depression of mutagenesis. Mutat Res 84: 273-282.

Curth U, Genschel J, Urbanke C, Greipel J (1996) In vitro and in vivo function of the C-terminus of Escherichia coli single-stranded DNA binding protein. Nucleic Acids Res 24: 2706-2711.

Dao M (1998) Mismatch-, MutS-, MutL-, and helicase II-dependent unwinding from the single-strand break of an incised heteroduplex. J Biol Chem 273: 9202-9207.

Digweed M, Sperling K (2004) Nijmegen breakage syndrome: clinical manifestation of defective response to DNA double-strand breaks. DNA Repair (Amst) 3: 1207-1217.

Dillingham MS, Spies M, Kowalczykowski SC (2003) RecBCD enzyme is a bipolar DNA helicase. Nature 423: 893-897.

Drablos F, Feyzi E, Aas PA, Vaagbo CB, Kavli B, Bratlie MS, Pena-Diaz J, Otterlei M, Slupphaug G, Krokan HE (2004) Alkylation damage in DNA and RNA-repair mechanisms and medical significance. DNA Repair (Amst) 3: 1389-1407.

Drees JC, Lusetti SL, Cox MM (2004b) Inhibition of RecA protein by the Escherichia coli RecX protein - Modulation by the RecA C terminus and filament functional state. J Biol Chem 279: 52991-52997.

Eastman A (1983) Characterization of the adducts produced in DNA by cis-diamminedichloroplatinum(II) and cis-dichloro(ethylenediamine)platinum(II). Biochemistry 22: 3927-3933.

Eggleston AK, West SC (2000) Cleavage of Holliday junctions by the Escherichia coli RuvABC complex. J Biol Chem 275: 26467-26476.

Einhorn LH (2002) Curing metastatic testicular cancer. Proc Natl Acad Sci USA 99: 4592-4595.

Fichtinger-Schepman AM, van der Veer JL, den Hartog JH, Lohman PH, Reedijk J (1985) Adducts of the antitumor drug cis-diamminedichloroplatinum(II) with DNA: formation, identification, and quantitation. Biochemistry 24: 707-713.

Flores MJ, Ehrlich SD, Michel B (2002) Primosome assembly requirement for replication restart in the Escherichia coli holDG10 replication mutant. Mol Microbiol 44: 783792.

Flores MJ, Bidnenko V, Michel B (2004) The DNA repair helicase UvrD is essential for replication fork reversal in replication mutants. EMBO Rep 5: 983-988.

Flores MJ, Sanchez N, Michel B (2005) A fork-clearing role for UvrD. Mol Microbiology 7: 1664-1675.

Fortin GS, Symington LS (2002) Mutations in yeast Rad51 that partially bypass the requirement for Rad55 and Rad57 in DNA repair by increasing the stability of Rad51-DNA complexes. EMBO J 21: 3160-3170.

Frappart PO, McKinnon PJ (2006) Ataxia-telangiectasia and related diseases. Neuromolecular Med 8: 495-511.

Friedberg EC, Walker GC, Siede W (1995) DNA repair and mutagenesis. ASM Press, Washington, D.C.
Gaillard PH, Noguchi E, Shanahan P, Russell P (2003) The endogenous Mus81-Eme1 complex resolves Holliday junctions by a nick and counternick mechanism. Mol Cell 12: 747-759.

Grompone G, Seigneur M, Ehrlich SD, Michel B (2002) Replication fork reversal in DNA polymerase III mutants of Escherichia coli: a role for the beta clamp. Mol Microbiol 44: 1331-1339.

Hanada K, Hickson ID (2007) Molecular genetics of RecQ helicase disorders. Cell Mol Life Sci 64: 2306-2322.

Hanada K, Ukita T, Kohno Y, Saito K, Kato J, Ikeda H (1997) RecQ DNA helicase is a suppressor of illegitimate recombination in Escherichia coli. Proc Natl Acad Sci USA 94: 3860-3865.

Handa N, Bianco PR, Baskin RJ, Kowalczykowski SC (2005) Direct visualization of RecBCD movement reveals cotranslocation of the RecD motor after chi recognition. Mol Cell 17: 745-750.

Heller RC, Marians KJ (2005) Unwinding of the nascent lagging strand by Rep and PriA enables the direct restart of stalled replication forks. J Biol Chem 280: 3414334151.

Heller RC, Marians KJ (2006) Replication fork reactivation downstream of a blocked nascent leading strand. $\mathrm{Na}$ ture 439: 557-562.

Heyer WD, Li X, Rolfsmeier M, Zhang XP (2006) Rad54: the Swiss Army knife of homologous recombination? Nucleic Acids Res 34: 4115-4125.

Hiom K, West SC (1995) Branch migration during homologous recombination: assembly of a RuvAB-Holliday junction complex in vitro. Cell 80: 787-793.

Hobbs MD, Cox MM (2007) SSB limits RecOR binding onto single strand DNA. J Biol Chem 282: 11058-11067.

Jaco I, Muñoz P, Goytisolo F, Wesoly J, Bailey S, Taccioli G, Blasco MA (2003) Role of mammalian Rad54 in telomere length maintenance. Mol Cell Biol 23: 5572-5580.

Jasin M (2002) Homologous repair of DNA damage and tumorigenesis: the BRCA connection. Oncogene 21: 8981-8993.

Johnson RD, Symington LS (1995) Functional differences and interactions among the putative RecA homologues Rad51, Rad55, and Rad57. Mol Cell Biol 15: 4843-4850.

Kaliraman V, Mullen JR, Frickle WM, Bastin-Shanover SA, Brill SJ (2001) Functional overlap between Sgs1-Top3 and the Mms4-Mus81 endonuclease. Genes Dev 15: 2730-2740.

Kojic M, Yang H, Kostrub CF, Pavletich NP, Holloman WK (2003) The BRCA2-interacting protein DSS1 is vital for DNA repair, recombination, and genome stability in Ustilago maydis. Mol Cell 12: 1043-1049.

Kolodner RD (2000) Guarding against mutation Nature 407: 687-689.

Koroleva O, Makharashvili N, Courcelle CT, Courcelle J, Korolev S (2007) Structural conservation of RecF and Rad50: implications for DNA recognition and RecF function. $E M B O J$ 26: 867-877.

Kowalczykowski SC (2000) Initiation of genetic recombination and recombination-dependent replication. Trends Biochem Sci 25: 156-165.

Kowalczykowski SC, Clow J, Somani R, Varghese A (1987) Effects of the Escherichia coli SSB protein on the binding of Escherichia coli RecA protein to single-stranded DNA. Demonstration of competitive binding and the lack of a specific protein-protein interaction. J Mol Biol 193: 81-95.

Kowalczykowski SC, Dixon DA, Eggleston AK, Lauder SD, Rehrauer WM (1994) Biochemistry of homologous recombination in Escherichia coli. Microbiol Rev 58: 401. 
Krwawicz J, Arczewska K, Speina E, Maciejewska A, Grzesiuk E (2007) Bacterial DNA repair genes and their eukaryotic homologues: 1. Mutations in genes involved in base excision repair (BER) and DNA end-processors and their implication in mutagenesis and human disease. Acta Biochim Polon 54: 413-434.

Kuzminov A (1999) Recombinational repair of DNA damaged in Escherichia coli and bacteriophage $\lambda$. Microbiol Mol Biol Rev 63: 751-813, table of contents.

Lahue RS, Au KG, Modrich P (1989) DNA mismatch correction in a defined system. Science 245: 160-164.

Lavery PS, Kowalczykowski SC (1990) Properties of recA441 protein-catalyzed DNA strand exchange can be attributed to an enhanced ability to compete with SSB protein. J Biol Chem 265: 4004-4010.

Little JW (1991) Mechanism of specific LexA cleavage: autodigestion and the role of RecA coprotease. Biochimie 73: 411-241.

Liu J, Marians K (1999) PriA-directed assembly of a primosome on D loop DNA. J Biol Chem 274: 25033-25041.

Liu Y, West SC (2004) Happy Hollidays: 40th anniversary of the Holliday junction. Nat Rev Mol Cell Biol 5: 937944.

Lloyd RG, Sharples GJ (1991) Molecular organization and nucleotide sequence of the recG locus of Escherichia coli K-12. J Bacteriol 173: 6837-6843.

Lloyd RG, Sharples GJ (1993) Processing of recombination intermediates by the RecG and RuvAB proteins of Escherichia coli. Nucleic Acids Res 21: 1719-1725.

Lohman TM, Bujalowski W (1994) Effects of base composition on the negative cooperativity and binding mode transitions of Escherichia coli SSB-single-stranded DNA complexes. Biochemistry 33: 6167-6176.

Lovett ST, Kolodner RD (1989) Identification and purification of a single-stranded-DNA-specific exonuclease encoded by the recJ gene of Escherichia coli. Proc Natl Acad Sci USA 86: 2627-2631.

Lovett ST, Sutera VA (1995) Suppression of recJ exonuclease mutants of Escherichia coli by alterations in DNA helicases II (UvrD) and IV (HelD). Genetics 140: 27-45.

Luisi-DeLuca C, Kolodner R (1994) Purification and characterization of the Escherichia coli $\mathrm{RecO}$ protein. Renaturation of complementary single-stranded DNA molecules catalyzed by the RecO protein. J Mol Biol 236: 124-138.

Lusetti SL, Voloshin ON, Inman RB, Camerini-Otero RD, Cox MM (2004) The DinI protein stabilizes RecA protein filaments. J Biol Chem 279: 30037-30046.

Lusetti SL, Hobbs MD, Stohl EA, Chitteni-Pattu S, Inman RB, Seifert HS, Cox MM (2006) The RecF protein antagonizes RecX function via direct interaction. Mol Cell 21: $41-50$.

Maddukuri L, Dudzińska D, Tudek B (2007) Bacterial DNA repair genes and their eukaryotic homologues: 4 . The role of nucleotide excision DNA repair (NER) system in mammalian cells. Acta Biochim Polon 54: 469-482.

Mathew CG (2006) Fanconi anemia genes and susceptibility to cancer. Onkogene 25: 5875-5884.

Matson SW (1986) Escherichia coli helicase II (urvD gene product) translocates unidirectionally in a $3^{\prime}$ to $5^{\prime} \mathrm{di}^{-}$ rection. J Biol Chem 261: 10169-10175.

McGlynn P, Lloyd RG (1999) RecG helicase activity at three- and four-strand DNA structures. Nucleic Acids Res 27: 3049-3056.

McGlynn P, Lloyd RG (2000) Modulation of RNA polymerase by (p)ppGpp reveals a RecG-dependent mechanism for replication fork progression. Cell 101: 35-45.

McGlynn P, Lloyd RG (2001) Rescue of stalled replication forks by RecG: simultaneous translocation on the leading and lagging strand templates supports an active
DNA unwinding model of fork reversal and Holliday junction formation. Proc Natl Acad Sci USA 98: 82278234.

McGlynn P, Mahdi AA, Lloyd RG (2000) Characterisation of the catalytically active form of RecG helicase. Nucleic Acids Res 28: 2324-2332.

McGlynn P, Lloyd RG, Marians KJ (2001) Formation of Holliday junctions by regression of nascent DNA in intermediates containing stalled replication forks: RecG stimulates regression even when the DNA is negatively supercoiled. Proc Natl Acad Sci USA 98: 8235-8240.

Meddows TR, Savory AP, Grove JI, Moore T, Lloyd RG (2005) RecN protein and transcription factor DksA combine to promote faithful recombinational repair of DNA double-strand breaks. Mol Microbiol 57: 97-110.

Mendonca VM, Kaiser-Rogers K, Matson SW (1993) Double helicase II (uvrD)-helicase IV (helD) deletion mutants are defective in the recombination pathways of Escherichia coli. J Bacteriol 175: 4641-4651.

Meyer RR, Laine PS (1990) The single-stranded DNA-binding protein of Escherichia coli. Microbiol Rev 54: 342-380.

Michel B, Flores MJ, Viguera E, Grompone G, Seigneur M, Bidnenko V (2001) Rescue of arrested replication forks by homologous recombination. Proc Natl Acad Sci USA 98: 8181-8188.

Miki Y, Swensen J, Shattuck-Eidens D, Futreal PA, Harshman K, Tavtigian S, Liu Q, Cochran C, Bennett LM, Ding W et. al. (1994) A strong candidate for the breast and ovarian cancer susceptibility gene BRCA1. Science 266: 66-71.

Mizukoshi T, Tanaka T, Arai K, Kohda D, Masai H (2003) A critical role of the $3^{\prime}$ terminus of nascent DNA chains in recognition of stalled replication forks. J Biol Chem 278: 42234-42239.

Morimatsu K, Kowalczykowski SC (2003) RecFOR proteins load RecA protein onto gapped DNA to accelerate DNA strand exchange: a universal step of recombinational repair. Mol Cell 11: 1337-1347.

Mortenson UH, Bendixen C, Sunjevaric I, Rothstein R (1996) DNA strand annealing is promoted by the yeast Rad52 protein. Proc Natl Acad Sci USA 93: 1072910734.

Nagashima K, Kubota Y, Shibata T, Sakaguchi C, Shinagawa H, Hishida T (2006) Degradation of Escherichia coli $\mathrm{RecN}$ aggregates by ClpXP protease and its implications for DNA damage tolerance. J. Biol Chem 281: 30941-30946.

New JH, Sugiyama T, Zaitseva E, Kowalczykowski SC (1998) Rad52 protein stimulates DNA strand exchange by Rad51 and replication protein A. Nature 391: 407410.

Nieminuszczy J, Grzesiuk E (2007) Bacterial DNA repair genes and their eukaryotic homologues: 3. AlkB dioxygenase and Ada methyltransferase in the direct repair of alkylated DNA. Acta Biochim Polon 54: 459-468.

Nowosielska A, Calmann MA, Zdraveski Z, Essigmann JM, Marinus MG (2004) Spontaneous and cisplatininduced recombination in Escherichia coli. DNA Repair (Amst) 3: 719-728.

Nowosielska A, Marinus MG (2005) Cisplatin induces DNA double-strand break formation in Escherichia coli dam mutants. DNA Repair (Amst) 12: 773-781.

Nowosielska A, Marinus MG (2007) DNA mismatch repair-induced double-strand breaks. DNA Repair (Amst) (Epub ahead of print).

Nowosielska A, Smith SA, Engelward BP, Marinus MG (2006) Homologous recombination prevents methylation-induced toxicity in Escherichia coli. Nucleic Acids Res 34: 2258-2268. 
Oakley TJ, Hickson ID (2002) Defending genome integrity during S-phase: putative roles for RecQ helicases and topoisomerase III DNA Repair (Amst) 1: 175-207.

Ogawa T, Yu X, Shinohara A, Egelman EH (1993) Similarity of the yeast RAD51 filament to the bacterial RecA filament. Science 259: 1896-1899.

Opresko PL, von Kobbe C, Laine JP, Harrigan J, Hickson ID, Bohr VA (2002) Telomere-binding protein TRF2 binds to and stimulates the Werner and Bloom syndrome helicases. J Biol Chem 277: 41110-41119.

Paques F, Haber JE (1999) Multiple pathways of recombination induced by double-strand breaks in Saccharomyces cerevisiae. Microbiol Mol Biol Rev 63: 349-404.

Pazin MJ, Kadonaga JT (1997) SWI2/SNF2 and related proteins: ATP-driven motors that disrupt protein-DNA interactions? Cell 88: 737-740.

Petranovic M, Zahradka K, Zahradka D, Petranovic D, Nagy B, Salaj-Smic E (2001) Genetic evidence that the elevated levels of Escherichia coli helicase II antagonize recombinational DNA repair. Biochimie 83: 1041-1047.

Pham P, Seitz EM, Saveliev S, Shen X, Woodgate R, Coc MM, Goodman MF (2002) Two distinct modes of RecA action are required for DNA polymerase V-catalyzed translesion synthesis. Proc Natl Acad Sci USA 99: 11061-11066.

Pinto AL, Lippard SJ (1985) Binding of the antitumor drug cis-diamminedichloroplatinum(II) (cisplatin) to DNA. Biochim Biophys Acta 780: 167-180.

Rangarajan S, Woodgate R, Goodman MF (2002) Replication restart in UV-irradiated Escherichia coli involving pols II, III, V, PriA, RecA and RecFOR proteins. Mol Microbiol 43: 617-628.

Reddy G, Golub EI, Radding CM (1997) Human Rad52 protein promotes single-strand DNA annealing followed by branch migration. Mutat Res 377: 53-59.

Rostas K, Morton SJ, Picksley SM, Lloyd RG (1987) Nucleotide sequence and LexA regulation of the Escherichia coli recN gene. Nucleic Acids Res 15: 5041-5049.

Runyon GT, Bear DG, Lohman TM (1990) Escherichia coli helicase II (UvrD) protein initiates DNA unwinding at nicks and blunt ends. Proc Natl Acad Sci USA 87: 63836387.

Sandler SJ (1996) Overlapping functions for recF priA in cell viability and UV-inducible SOS expression are distinguished by dnaC809 in Escherichia coli K-12. Mol Microbiol 19: 871-880.

Sandler SJ (2000) Multiple genetic pathways for restarting DNA replication forks in Escherichia coli K-12. Genetics 155: 487-497.

Sandler SJ, Clark AJ (1994) Mutational analysis of sequences in the recF gene of Escherichia coli K-12 that affect expression. J Bacteriol 176: 4011-4016.

Sandler SJ, McCool JD, Do TT, Johansen RU (2001) PriA mutations that affect PriA-PriC function during replication restart. Mol Microbiol 41: 697-704.

Schlacher K, Cox MM, Woodgate R, Goodman MF (2006) RecA acts in trans to allow replication of damaged DNA by DNA polymerase V. Nature 442: 883-887.

Seigneur M, Bidnenko V, Ehrlich SD, Michel B (1998) RuvAB acts at arrested replication forks. Cell 95: 419-430.

Seigneur M, Ehrlich SD, Michel B (2000) RuvABC-dependent double-strand breaks in dnaBts mutants require recA. Mol Microbiol 38: 565-574.

Shan Q, Cox MM (1996) RecA protein dynamics in the interior of RecA nucleoprotein filaments. J Mol Biol 257: 756-774.

Shan Q, Cox MM (1997) RecA protein filaments: end-dependent dissociation from ssDNA and stabilization by RecO and RecR proteins. J Mol Biol 265: 519-540.
Sharma S, Doherty KM, Brosh RM Jr. (2006) Mechanisms of RecQ helicases in pathways of DNA metabolism and maintenance of genomic stability. Biochem J 398: 319-337.

Sharples GJ, Bolt EL, Lloyd RG (2002) RusA proteins from the extreme thermophile Aquifex aeolicus and lactococcal phage r1t resolve Holliday junctions. Mol Microbiol 44: 549-559.

Shinohara A, Ogawa T (1998) Stimulation by Rad52 of yeast Rad51-mediated recombination. Nature 391: 404407.

Shinohara A, Ogawa H, Ogawa T (1992) Rad51 protein involved in repair and recombination in $S$. cerevisiae is a RecA-like protein. Cell 69: 457-470.

Shinohara A, Shinohara M, Ohta T, Matsuda S, Ogawa $\mathrm{T}$ (1998) Rad52 forms ring structures and co-operates with RPA in single-strand DNA annealing. Genes Cells 3: $145-156$.

Story RM, Weber IT, Steitz TA (1992) The structure of the E. coli RecA protein monomer and polymer. Nature 355: 318-325.

Sugiyama T, New JH, Kowalczykowski SC (1998) DNA annealing by RAD52 protein is stimulated by specific interaction with the complex of replication protein A and single-stranded DNA. Proc Natl Acad Sci USA 95: 6049-6054.

Sung P (1997) Yeast Rad55 and Rad57 proteins form a heterodimer that functions with replication protein A to promote DNA strand exchange by Rad51 recombinase. Genes Dev 11: 1111-1121.

Sung P, Krejci L, Van Komen S, Sehorn MG (2003) Rad51 recombinase and recombination mediators. J Biol Chem 278: 42729-42732.

Symington LS (2002) Role of RAD52 epistasis group genes in homologous recombination and double-strand break repair. Microbiol Mol Biol Rev 66: 630-670.

Tang MJ, Shen X, Frank EG, O'Donnell M, Woodgate R, Goodman MF (1999) UmuD'(2)C is an error-prone DNA polymerase, Escherichia coli pol V. Proc Natl Acad Sci USA 96: 8919-8924.

Tarsounas M, Munoz P, Claas A, Smiraldo PG, Pittman DL, Blasco MA, West SC (2004) Telomere maintenance requires the RAD51D recombination/repair protein. Cell 117: 337-347.

Taylor A, Smith GR (1980) Unwinding and rewinding of DNA by the RecBC enzyme. Cell 22 (Pt 2): 447-457.

Taylor AF, Smith GR (2003) RecBCD enzyme is a DNA helicase with fast and slow motors of opposite polarity. Nature 423: 889-893.

Tsaneva IR, Illing G, Lloyd RG, West SC (1992) Purification and properties of the RuvA and RuvB proteins of Escherichia coli. Mol Gen Genet 235: 1-10.

Umezu K, Kolodner RD (1994) Protein interactions in genetic recombination in Escherichia coli. Interactions involving $\mathrm{RecO}$ and RecR overcome the inhibition of RecA by single-stranded DNA-binding protein. I Biol Chem 269: 30005-30013.

Van Komen S, Reddy MS, Krejci L, Klein H, Sung P (2003) ATPase and DNA helicase activities of the Saccharomyces cerevisiae anti-recombinase Srs2. J Biol Chem 278: 44331-44337.

Veaute X, Delmas P, Selva M, Jeusset J, Cam ELe, Matic I, Fabre F, Petit MA (2005) UvrD helicase, unlike Rep helicase, dismantles RecA nucleoprotein filaments in Escherichia coli. EMBO J 24: 180-189.

Webb BL, Cox MM, Inman RB (1999) ATP hydrolysis and DNA binding by the Escherichia coli RecF protein. J Biol Chem 274: 15367-15374. 
West SC (1997) Processing of recombination intermediates by the RuvABC proteins. Annu Rev Genet 31: 213-244.

West SC (2003) Molecular views of recombination proteins and their control. Nat Rev Mol Cell Biol 4: 435-445.

Wolner B, van Komen S, Sung P, Peterson CL (2003) Recruitment of the recombinational repair machinery to a DNA double-strand break in yeast. Mol Cell 12: 221232.

Wooster R, Bignell G, Lancaster J, Swift S, Seal S, Mangion J, Collins N, Gregory S, Gumbs C, Micklem G (1995)
Identification of the breast cancer susceptibility gene BRCA2. Nature 378: 789-792.

Yang H, Jeffrey PD, Miller J, Kinnucan E, Sun Y, Thoma NH, Zheng N, Chen PL, Lee WH, Pavletich NP (2002) BRCA2 function in DNA binding and recombination from a BRCA2-DSS1-ssDNA structure. Science 297: 1837-1848.

Zdraveski ZZ, Mello JA, Marinus MG, Essigmann JM et al. (2000) Multiple pathways of recombination define cellular responses to cisplatin. Chem Biol 7: 39-50. 